\title{
On an early demonstration of the cell boundary theorem
}

\author{
Eduardo Ríos
}

Received: 2 December 2012/Accepted: 2 December 2012/Published online: 22 December 2012

(C) The Physiological Society of Japan and Springer Japan 2012

Editors,

As stated in Prof. Friel's letter, the paper by Friel and Tsien [1] includes a rigorous demonstration of what I recently called the cell boundary theorem [2].

I proposed the theorem to formalize an old idea, two early versions of which were cited as examples [2]. I regret that I missed the earlier formalism and demonstration.

I am also addressing all corresponding authors who have cited [2] to make them aware of the earlier work.

\section{References}

1. Friel DD, Tsien RW (1992) A caffeine- and ryanodine-sensitive $\mathrm{Ca}^{2+}$ store in bullfrog sympathetic neurones modulates effects of $\mathrm{Ca}^{2+}$ entry on $\left[\mathrm{Ca}^{2+}\right]_{\mathrm{i}}$. J Physiol 450:217-246

2. Rios E (2010) The cell boundary theorem: a simple law of the control of cytosolic calcium concentration. J Physiol Sci 60:81-84

E. Ríos $(\square)$

Department of Molecular Biophysics and Physiology,

Section of Cellular Signaling, Rush University,

Chicago, USA

e-mail: erios@rush.edu 